\title{
Model-based projection of health and economic effects of screening for hepatitis $\mathrm{C}$ in Canada
}

\author{
William W.L. Wong PhD, Aysegul Erman MSc, Jordan J. Feld MD, Murray Krahn MD MSc
}

\section{Abstract}

Background: Because most hepatitis $\mathrm{C}$ virus $(\mathrm{HCV})$ infections are asymptomatic and often unrecognized, screening for hepatitis $\mathrm{C}$ has been proposed as a plausible public health strategy. We examined the health and economic consequences of a selective onetime hepatitis $\mathrm{C}$ screening program for specific populations in the context of current treatment patterns.

Methods: We used a state-transition model to evaluate 2 general strategies: no screening, and screen and treat with direct-acting antiviral agents. We examined these strategies for 4 different target populations (scenarios): 1) asymptomatic people not at high risk for HCV infection, 2) immigrant populations with high prevalence, 3) a birth cohort of people aged 25-64 years and 4) a birth cohort of people aged 45-64 years of age. We obtained model data from the published literature and expert opinions. We used a payer perspective, a lifetime time horizon and a $5 \%$ discount rate.

Results: Screening would prevent $49.7 \%, 57.4 \%, 64.1 \%$ and $49.6 \%$ of HCV-related deaths over the lifetime of the cohort for scenarios 1, 2, 3 and 4, respectively. Screening would produce incremental-cost-effectiveness ratios between $\$ 31468 / q u a l i t y-$ adjusted life-year and $\$ 50$ 490/quality-adjusted life-year. Probabilistic sensitivity analyses indicated that the chance that screening would be cost-effective at $\$ 50000$ willingness-to-pay threshold was $39.5 \%, 63.2 \%, 58.4 \%$ and $58.1 \%$ for scenarios $1,2,3$ and 4 , respectively.

Interpretation: Our analyses suggest that a one-time hepatitis $\mathrm{C}$ screening and treatment program in Canada is likely to be costeffective for scenarios 2, 3 and 4. The screening programs we have evaluated would identify asymptomatic people with chronic HCV infection and would enable medical treatment to be offered if needed before the development of advanced liver disease.

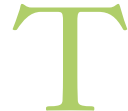
he growing burden of chronic infection with hepatitis $\mathrm{C}$ virus (HCV) poses a significant public health concern. In a 2010 study from Ontario, hepatitis C was ranked first among all infectious diseases in healthrelated burden of illness. ${ }^{1}$ Because most chronic HCV infections are asymptomatic, many infections remain undiagnosed until the later stages of disease. Canadian estimates suggest that chronic HCV infection remains undiagnosed in $45 \%-$ $70 \%$ of people., ${ }^{2,3}$ Early diagnosis and treatment may reduce complications associated with late-stage disease. ${ }^{4}$ Therefore, targeted HCV screening could be a plausible strategy.

In 2014, the Public Health Agency of Canada commissioned the development of a state-transition model to examine the cost-effectiveness of various screening strategies for hepatitis C. ${ }^{5}$ The analyses suggested that a selective one-time screening program for people aged 25-64 years and 45-64 years in Canada would likely be cost-effective. ${ }^{5}$

Since 2014, the availability of interferon-free directacting antivirals has transformed the treatment of $\mathrm{HCV}$ infection, offering high cure rates (defined by sustained virologic response, typically at 12 or $24 \mathrm{wk}$ ) with markedly improved tolerability. Although treatment with interferon-free direct-acting antivirals has been shown to be cost-effective in selected populations, ${ }^{6}$ their high cost together with the decreasing prevalence of chronic HCV infection and its low incidence creates a unique situation in which price inflexibility and budget constraints may necessitate limits on access to treatment. ${ }^{7}$ Most Canadian reimbursement programs restrict eligibility to patients with moderate to advanced liver fibrosis. $^{7}$ This would be further complicated if infections were diagnosed earlier and more comprehensively through population screening. Thus, the benefit of the hepatitis $\mathrm{C}$ screening program becomes uncertain. To improve the efficiency

Competing interests: William Wong and Murray Krahn have received research support from the Canadian Liver Foundation; Jordan Feld has received consulting fees and research support from AbbVie, Gilead Sciences, Janssen and Merck. No other competing interests were declared.

This article has been peer reviewed.

Correspondence to: William Wong, wwlwong@uwaterloo.ca CMAJ Open 2017. DOI:10.9778/cmajo.20170048 
of screening, some countries have adopted targeted screening in populations with higher prevalence, such as immigrants from $\mathrm{HCV}$-endemic regions or birth cohorts with higher prevalence, such as those born between 1945 and 1965.

In anticipation of the need for supporting evidence on the health and economic consequences of hepatitis C screening, and to assist the Canadian Task Force on Preventive Health Care (CTFPHC) in making up-to-date recommendations, ${ }^{8}$ we updated our state-transition model with new parameters and ran new scenario analyses to reexamine the health and economic consequences of a selective one-time hepatitis $\mathrm{C}$ screening program for specific populations.

\section{Methods}

We used a previously developed and validated state-transition model, following the same approach as previously described, ${ }^{5}$ to examine the health and economic effects of 2 general screening strategies: no screening, and screen and treat with direct-acting antiviral agents. A full description of the methods is available in Appendix 1 (available at www.cmajopen.ca/ content/5/3/E662/suppl/DC1).

\section{Cohort}

We examined 4 different cohorts under consideration by the CTFPHC: ${ }^{8} 1$ ) asymptomatic people not at high risk for HCV infection, 2) immigrant populations with high prevalence, 3) birth cohort aged 25-64 years and 4) birth cohort aged 45-64 years. Detailed descriptions of the cohorts are provided in Table 1, and important parameters such as the prevalence associated with each cohort are provided in Table 2 and Table 3.

\section{Strategies}

In our baseline analysis, for each cohort, we considered the following screening strategies:

- No screening, treat with direct-acting antiviral if HCV infection diagnosed: depending on different scenarios, we assumed that a certain proportion of $\mathrm{HCV}$-infected people are initially unaware of their infection and do not receive antiviral treatment. We assumed that, each year, $0.68 \%$ of this group would discover that they are chronically infected with $\mathrm{HCV}^{15}$ and might undergo treatment. If $\mathrm{HCV}$ infection remains undetected, we assumed that liver disease would be detected when decompensated cirrhosis and/or hepatocellular carcinoma developed.

- Screen and treat with direct-acting antiviral: people would be offered one-time screening for HCV through their primary care physician at a visit scheduled for another purpose. This represents a "case-finding" strategy (i.e., only targeted people matching the cohort definitions [Table 1] would be invited). Screening involves a blood test for $\mathrm{HCV}$ antibody. All positive antibody test results would be followed by an HCV RNA test to confirm infection. Our analysis assumed that all people with positive results for both tests would be referred to a specialist and might be

offered treatment with a direct-acting antiviral according to the Canadian guidelines. ${ }^{16}$

\section{Treatment}

We assumed that patients with genotype 1 infection would be treated with 12 weeks of dasabuvir plus ombitasvirparitaprevir-ritonavir or ledipasvir plus sofosbuvir, those with genotype 2 infection would be treated with 12 weeks of sofosbuvir plus ribavirin, those with genotype 3 infection would be treated with 24 weeks of sofosbuvir plus ribavirin, and those with all other genotypes would receive pegylated interferon-ribavirin. In addition, in an exploratory analysis, we assumed that patients with genotype 4, 5 or 6 infection would receive 12 weeks of sofosbuvir plus velpatasvir. In our base-case analysis, we also assumed that treatment reimbursement restrictions ${ }^{7}$ were imposed for patients with stage F0 or F1 fibrosis whereby patients in this subgroup in whom $\mathrm{HCV}$ infection was diagnosed were not treated with the interferon-free direct-acting antiviral immediately but, rather, were followed and offered treatment on progression to stage $\mathrm{F} 2$ or above. ${ }^{7}$

\section{Decision model}

In our analysis, we developed a cohort-based state-transition model using TreeAge Pro 2016 software. ${ }^{17}$ In our simulations, cohort members transitioned between predefined health states in weekly cycles until all members died. Health states and allowed transitions among health states are shown in Figure 1.

\section{Model parameters}

We parameterized the existing model with values suggested by the CTFPHC and validated by clinical experts. ${ }^{8}$ Specifically, the important parameters included prevalence, ${ }^{2,3}$ uptake of screening, distribution of the disease stages (fibrosis stages

\section{Table 1: Definition of cohorts under consideration for} screening for HCV infection ${ }^{8}$

Cohort Definition

Asymptomatic people not at high risk for $\mathrm{HCV}$ infection

Immigrant populations with high prevalence
Non-Aboriginal, nonimmigrant asymptomatic people (not suspected of having HCV infection) aged 15-79 yr living in Canada

People aged 15-79 yr granted the right to live in Canada permanently (including all landed immigrants, permanent residents, refugees and granted Canadian citizens); excludes those born outside Canada who are Canadian citizens by birth

Specific birth cohort People aged 25-64 yr living in Canada (25-64 yr)

Specific birth cohort People aged 45-64 yr living in Canada (45-64 yr)

Note: $\mathrm{HCV}=$ hepatitis $\mathrm{C}$ virus. 


\begin{tabular}{|c|c|c|c|c|}
\hline \multirow[b]{2}{*}{ Parameter } & \multicolumn{4}{|c|}{ Scenario } \\
\hline & $\begin{array}{l}\text { 1. Asymptomatic } \\
\text { people not at high risk } \\
\text { for HCV infection }\end{array}$ & $\begin{array}{l}\text { 2. Immigrant } \\
\text { populations with high } \\
\text { prevalence }\end{array}$ & $\begin{array}{l}\text { 3. Specific birth cohort } \\
\text { (25-64 yr) }\end{array}$ & $\begin{array}{l}\text { 4. Specific birth cohort } \\
(45-64 \mathrm{yr})\end{array}$ \\
\hline $\begin{array}{l}\text { Cost of dasabuvir plus } \\
\text { ombitasvir-paritaprevir- } \\
\text { ritonavir, } \$^{9}\end{array}$ & 55860 & 55860 & 55860 & 55860 \\
\hline $\begin{array}{l}\text { Cost of ledipasvir plus } \\
\text { sofosbuvir, } \$^{9}\end{array}$ & 67000 & 67000 & 67000 & 67000 \\
\hline $\begin{array}{l}\text { Cost of pegylated interferon- } \\
\text { ribavirin, } \$^{9}\end{array}$ & 19075 & 19075 & 19075 & 19075 \\
\hline $\begin{array}{l}\text { Prevalence of } \mathrm{HCV} \text { infection } \\
\text { (range) }\end{array}$ & $0.2(0.10-0.30)^{3}$ & $1.9(1.30-2.60)^{3}$ & $\begin{array}{l}14-49 \text { yr: } 0.4(0.2-0.7) \\
50-79 \text { yr: } 0.8(0.4-1.5)^{2}\end{array}$ & $\begin{array}{l}14-49 \text { yr: } 0.4(0.2-0.7) \\
50-79 \text { yr: } 0.8(0.4-1.5)^{2}\end{array}$ \\
\hline $\begin{array}{l}\text { Uptake of screening (range), } \\
\%^{*}\end{array}$ & $89.5(70-100)$ & $76.6(60-100)$ & $89.5(60-100)$ & $90(76-100)$ \\
\hline $\begin{array}{l}\text { Uptake of treatment (range), } \\
\%^{*}\end{array}$ & $80(80-100)$ & $95(80-100)$ & $95(80-100)$ & $80(80-100)$ \\
\hline $\begin{array}{l}\text { Known chronic HCV } \\
\text { infection }^{2}\end{array}$ & 0.305 & 0.305 & 0.305 & 0.305 \\
\hline \multirow[t]{7}{*}{ Age distribution ${ }^{10}$} & $15-24$ yr: 0.17 & $15-24$ yr: 0.10 & 25-34 yr: 0.20 & $45-54$ yr: 0.54 \\
\hline & $25-34$ yr: 0.17 & $25-34$ yr: 0.15 & $35-44$ yr: 0.27 & 55-64 yr: 0.46 \\
\hline & $35-44$ yr: 0.17 & $35-44$ yr: 0.21 & $45-54$ yr: 0.29 & - \\
\hline & $45-54$ yr: 0.20 & $45-54$ yr: 0.22 & 55-64 yr: 0.24 & - \\
\hline & 55-64 yr: 0.16 & $55-64$ yr: 0.19 & - & - \\
\hline & $65-74$ yr: 0.10 & $65-74$ yr: 0.10 & - & - \\
\hline & $75-79$ yr: 0.03 & $75-79$ yr: 0.03 & - & - \\
\hline $\begin{array}{l}\text { Distribution of fibrosis stage } \\
\text { for all cohorts (range), \%* }\end{array}$ & Age 15-34 yr & Age 35-44 yr & Age $45-54$ yr & Age 55-79 yr \\
\hline Fo & $45(30-35)$ & $10(5-15)$ & $5(0-10)$ & $5(0-10)$ \\
\hline $\mathrm{F} 1$ & $45(30-55)$ & $43(30-60)$ & $25(15-30)$ & $10(5-15)$ \\
\hline $\mathrm{F} 2$ & $8(5-20)$ & $13(13-60)$ & $25(25-45)$ & $15(10-20)$ \\
\hline F3 & $1(0-5)$ & $19(5-20)$ & $25(20-30)$ & $45(40-60)$ \\
\hline $\mathrm{F} 4$ & $1(0-5)$ & $15(0-20)$ & $20(5-35)$ & $25(15-40)$ \\
\hline
\end{tabular}

at diagnosis) and uptake of treatment (which takes into account loss to follow-up before treatment initiation). Table 2 and Table 3 present the key parameter values for each scenario. We updated all data on efficacy and adverse effects based on the findings of the current Canadian Agency for Drugs and Technologies in Health therapeutic review ${ }^{9,11}$ (Table 3). Data for all other parameters were collected from the literature ${ }^{5,12-14}$ (Appendix 1).

\section{Economic assumptions}

The analyses were carried out from the payer perspective and were structured as a cost-utility analysis. Future costs and health benefits were discounted at 5\% annually. We inflated all cost data to 2015 using the Statistics Canada Consumer Price Index for health care and personal items.

\section{Model validation}

For validation purposes, we ran our model using the baseline parameter values and compared the predicted outcomes of our model against published studies. ${ }^{18-20}$

\section{Results}

\section{Base case}

Scenario 1: screening asymptomatic people not at high risk for HCV infection (Figure 2)

In our baseline estimate for people aged 15-79 years, the screen-and-treat strategy is more costly but also more effective than no screening (Table 4). For every 100000 people screened, around 199 cases of $\mathrm{HCV}$ infection would be 


\begin{tabular}{|c|c|c|c|c|}
\hline Parameter & Description & $\begin{array}{l}\text { Baseline† or } \\
\text { RR }\end{array}$ & $\begin{array}{l}\text { Lower limit } \\
(95 \% \mathrm{Crl})\end{array}$ & $\begin{array}{l}\text { Upper limit } \\
(95 \% \text { Crl) }\end{array}$ \\
\hline \multicolumn{5}{|l|}{$\begin{array}{l}\text { Treatment efficacy (sustained virologic } \\
\text { response) }\end{array}$} \\
\hline \multicolumn{5}{|l|}{ Genotype 1} \\
\hline \multicolumn{5}{|l|}{ Noncirrhosis } \\
\hline Reference baseline PR48 & Pegylated interferon + ribavirin for 48 wk & $0.4913 \dagger$ & 0.4359 & 0.5456 \\
\hline SOF12 + LDV12 & Sofosbuvir + ledipasvir for 12 wk & 1.978 & 1.78 & 2.225 \\
\hline PAR/RIT12 + OMB12 + DAS12 & $\begin{array}{l}\text { Paritaprevir-ritonavir + ombitasvir + } \\
\text { dasabuvir for } 12 \mathrm{wk}\end{array}$ & 1.932 & 1.337 & 2.211 \\
\hline \multicolumn{5}{|l|}{ Cirrhosis } \\
\hline Reference baseline PR48 & & $0.3898 \dagger$ & 0.3099 & 0.475 \\
\hline SOF12 + LDV12 & & 2.442 & 1.956 & 3.091 \\
\hline $\begin{array}{l}\text { PAR/RIT12 + OMB12 + DAS12 + } \\
\text { RBV12 }\end{array}$ & $\begin{array}{l}\text { Paritaprevir-ritonavir + ombitasvir + } \\
\text { dasabuvir + ribavirin for } 12 \mathrm{wk}\end{array}$ & 2.416 & 1.942 & 3.057 \\
\hline \multicolumn{5}{|l|}{ Genotype 2} \\
\hline \multicolumn{5}{|l|}{ Noncirrhosis } \\
\hline SOF12 + RBV12 & Sofosbuvir + ribavirin for $12 \mathrm{wk}$ & 1.16 & 1.083 & 1.244 \\
\hline Reference baseline PR24 & Pegylated interferon + ribavirin for 24 wk & $0.8191 \dagger$ & 0.7687 & 0.8619 \\
\hline \multicolumn{5}{|l|}{ Cirrhosis } \\
\hline SOF12 + RBV12 & & 1.375 & 1.026 & 1.791 \\
\hline Reference baseline PR24 & & $0.6209 \dagger$ & 0.4966 & 0.7344 \\
\hline \multicolumn{5}{|l|}{ Genotype 3} \\
\hline \multicolumn{5}{|l|}{ Noncirrhosis } \\
\hline Reference baseline PR48 & & $0.7051 \dagger$ & 0.6393 & 0.765 \\
\hline SOF24 + RBV24 & Sofosbuvir + ribavirin for 24 wk & 1.318 & 1.177 & 1.47 \\
\hline DCV12 + SOF12 & Daclatasvir + sofosbuvir for $12 \mathrm{wk}$ & 1.375 & 1.233 & 1.525 \\
\hline \multicolumn{5}{|l|}{ Cirrhosis } \\
\hline Reference baseline PR48 & & $0.6021 \dagger$ & 0.5584 & 0.6441 \\
\hline SOF24 + RBV24 & & 1.509 & 1.142 & 1.702 \\
\hline \multicolumn{5}{|l|}{ Genotypes 4-6 } \\
\hline PR48 & & 0.65 & 0.57 & 0.71 \\
\hline
\end{tabular}

identified, which would prevent $40 \mathrm{HCV}$-related deaths over the lifetime of the cohort. Thus, 2500 people would need to be screened to prevent $1 \mathrm{HCV}$-related death. Figure 2 summarizes the trends of the liver-related health events per 100000 people screened accumulated over time. The screen-and-treat strategy would result in a net cost increment of about $\$ 102$ and 0.0020 quality-adjusted life-years (QALYs) gained per person (or 0.0087 undiscounted life-years) (Appendix 1, Supplementary Table 3), which translates to an incremental cost-effectiveness ratio (ICER) of \$50 490/QALY gained compared to no screening. Table 4 summarizes the cost-effectiveness results.

\section{Scenario 2: screening high-prevalence immigrant} populations (Figure 3 )

For every 100000 people screened, around 1661 cases of $\mathrm{HCV}$ infection would be identified, which would prevent at least $414 \mathrm{HCV}$-related deaths over the lifetime of the cohort. Thus, 242 people would need to be screened to prevent $1 \mathrm{HCV}$-related death. The screen-and-treat strategy would result in a net cost increment of about $\$ 619$ and 0.0197 QALYs gained per person (or 0.0792 undiscounted life year (Appendix 1, Supplementary Table 3), which translates to an ICER of \$31 468/QALY gained compared to no screening.

\section{Scenario 3: screening birth cohort of those aged 25-64 years (Figure 4)}

If the screening program targeted the birth cohort of people aged 25-64 years, for every 100000 people screened, around 582 cases of $\mathrm{HCV}$ infection would be identified, which would prevent at least $148 \mathrm{HCV}$-related deaths over the lifetime of the cohort. Thus, 676 people would need to be screened to prevent $1 \mathrm{HCV}$-related death. The screen-and- 


\section{OPEN}

Research

Table 3 (part 2 of 2): Treatment-related parameters used in the model*

\begin{tabular}{|c|c|c|c|c|}
\hline Parameter & Description & $\begin{array}{c}\text { Baseline } \uparrow \text { or } \\
\text { RR }\end{array}$ & $\begin{array}{l}\text { Lower limit } \\
\text { (95\% Crl) }\end{array}$ & $\begin{array}{l}\text { Upper limit } \\
(95 \% \mathrm{Crl})\end{array}$ \\
\hline
\end{tabular}

\section{Adverse events (treatment-naive \\ people)}

\section{Depression}

\begin{tabular}{|c|c|c|c|}
\hline Reference baseline PR48 & $0.1381 \dagger$ & 0.11 & 0.1683 \\
\hline SOF12 + RBV12 & 0.2861 & 0.07992 & 0.958 \\
\hline SOF24 + RBV24 & 0.7751 & 0.165 & 3.181 \\
\hline SOF12 + LDV12 & 0.01888 & 0.002205 & 0.09946 \\
\hline PAR/RIT12 + OMB12 + DAS12 + RBV12 & 0.4174 & 0.08099 & 1.534 \\
\hline PR24 & 0.756 & 0.1592 & 2.831 \\
\hline \multicolumn{4}{|l|}{ Anemia } \\
\hline Reference baseline PR48 & $0.2136 \dagger$ & 0.1838 & 0.2459 \\
\hline SOF12 + RBV12 & 0.6949 & 0.3601 & 1.309 \\
\hline SOF24 + RBV24 & 1.263 & 0.4806 & 2.528 \\
\hline SOF12 + LDV12 & 0.05568 & 0.02193 & 0.1322 \\
\hline PAR/RIT12 + OMB12 + DAS12 & 0.3454 & 0.1431 & 0.7469 \\
\hline PAR/RIT12 + OMB12 + DAS12 + RBV12 & 0.3826 & 0.1549 & 0.8366 \\
\hline PR24 & 0.9708 & 0.4121 & 2.065 \\
\hline \multicolumn{4}{|l|}{ Rash } \\
\hline Reference baseline PR48 & $0.1828 \dagger$ & 0.1465 & 0.2186 \\
\hline SOF12 + RBV12 & 0.5244 & 0.167 & 1.598 \\
\hline SOF24 + RBV24 & 0.7655 & 0.07902 & 2.721 \\
\hline SOF12 + LDV12 & 0.2626 & 0.1415 & 0.4803 \\
\hline PAR/RIT12 + OMB12 + DAS12 & 0.2194 & 0.08837 & 0.525 \\
\hline PAR/RIT12 + OMB12 + DAS12 + RBV12 & 0.7214 & 0.3777 & 1.301 \\
\hline PR24 & 1.03 & 0.3068 & 2.839 \\
\hline Treatment discontinuation rate & $\begin{array}{c}\text { Base } \\
\text { estimate }\end{array}$ & $\begin{array}{l}\text { Lower limit } \\
(95 \% \mathrm{Cl})\end{array}$ & $\begin{array}{c}\text { Upper limi } \\
(95 \% \mathrm{Cl})\end{array}$ \\
\hline PR48 & 0.173 & 0.096 & 0.292 \\
\hline SOF12 + RBV12 & 0.089 & 0.038 & 0.194 \\
\hline SOF24 + RBV24 & 0.054 & 0.015 & 0.18 \\
\hline SOF12 + LDV12 & 0.044 & 0.023 & 0.083 \\
\hline PAR/RIT12 + OMB12 + DAS12 & 0.005 & 0.001 & 0.033 \\
\hline PAR/RIT12 + OMB12 + DAS12 + RBV12 & 0.015 & 0.003 & 0.071 \\
\hline
\end{tabular}

treat strategy would result in a net cost increment of roughly \$261 and 0.0080 QALYs gained per person, which translates to an ICER of $\$ 32712$ QALY gained compared to no screening.

Scenario 4: screening birth cohort of those aged 45-64 years (Figure 5)

Alternatively, if the screening program targeted the birth cohort of those aged 45-64 years, among whom the prevalence of $\mathrm{HCV}$ infection is higher, for every 100000 people screened, around 769 cases of HCV infection would be identified. This would prevent at least $163 \mathrm{HCV}$-related deaths over the lifetime of the cohort. Thus, 613 people would need to be screened to prevent $1 \mathrm{HCV}$-related death. The screen-and-treat strategy would result in a net cost increment of about \$304 and 0.0088 QALYs gained per person, which translates to an ICER of \$34 614/QALY gained compared to no screening. 


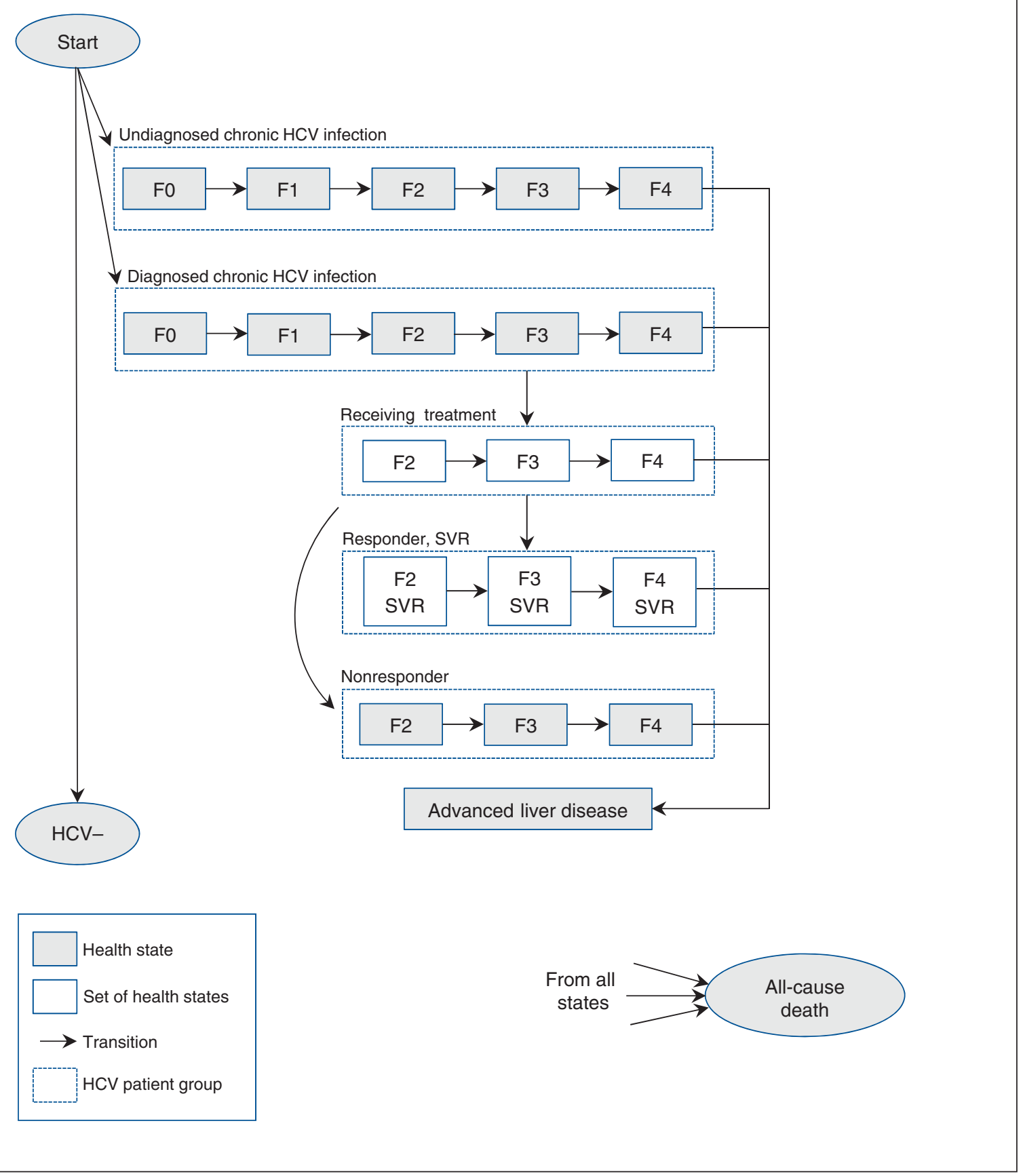

Figure 1: State-transition model of hepatitis C virus $(\mathrm{HCV})$ infection and progression. See Appendix 1, Supplementary Figure 1 for details of set of health states. Note: $\mathrm{F} 0=$ no fibrosis, $\mathrm{F} 1=$ portal fibrosis without septa, $\mathrm{F} 2=$ portal fibrosis with rare septa, $\mathrm{F} 3=$ numerous septa without cirrhosis, F4 = cirrhosis, SVR = sustained virologic response.

Appendix 1, Supplementary Table 4 summarizes the total estimated net health gain for each scenario. Of the 4 scenarios, scenarios 2 and 3 would produce the largest net health gain.

\section{Sensitivity analyses}

We performed both one-way deterministic sensitivity analyses and probabilistic sensitivity analyses to explore the impact of the model's parameter uncertainty.

\section{Deterministic sensitivity analyses}

Tornado diagrams in Appendix 2 (available at www.cmajopen. $\mathrm{ca} /$ content/5/3/E662/suppl/DC1) and the cost-effectiveness results by screening age groups in Appendix 1, Supplementary Figure 2 summarize the results of the deterministic sensitivity analyses for all scenarios.

In general, varying age and chronic HCV infection utilities had the largest effect on the main results. For example, when 


\section{OPEN}

Research

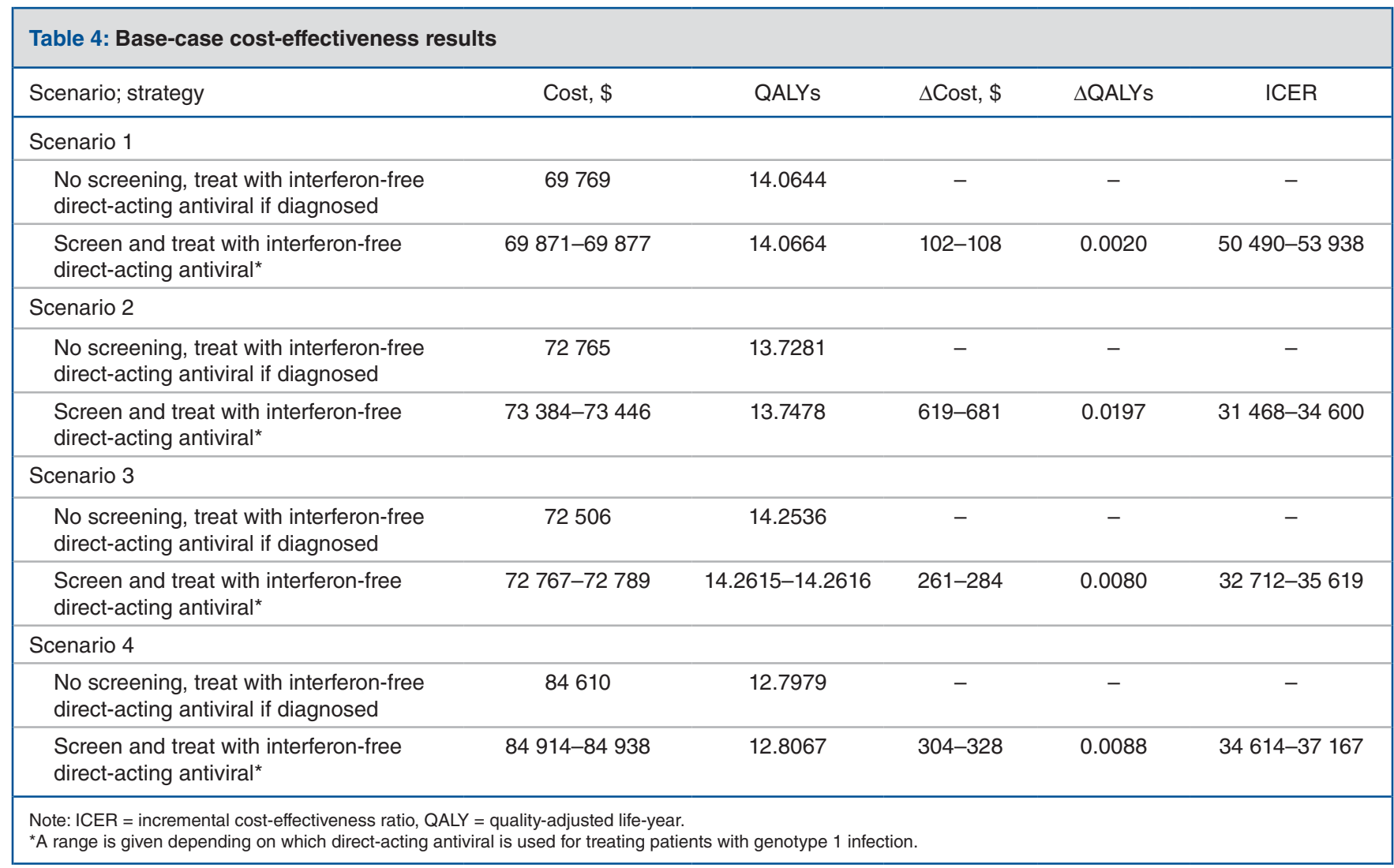

we varied age, the ICER for scenario 1 ranged from $\$ 40162$ / QALY to \$154 750/QALY. When we varied chronic HCV infection utilities, the ICER for scenario 1 ranged from \$51 816/QALY to \$73 430/QALY.

When we varied screening-related parameters such as prevalence, screening acceptance rate, known HCV infection rate and the cost of screening, the ICER for scenario 1 ranged from $\$ 48$ 233/QALY to \$76 061/QALY. The sensitivity analysis results indicated that the ICER for scenario 1 would be less than $\$ 50$ 000/QALY if the prevalence were greater than $0.2 \%$.

We also conducted additional sensitivity analyses regarding 1) a sustained virologic response progression/reinfection assumption, where we assumed that $8.6 \%{ }^{21}$ will continue to progress even after achieving sustained virologic response, and 2) the assumption of relaxing the restriction on treatment for patients with stage F0 or F1 fibrosis. Sensitivity analyses for both of these assumptions indicated that the main conclusions will not change significantly under these new assumptions.

\section{Probabilistic sensitivity analyses}

Our probabilistic sensitivity analyses for scenarios 1, 2, 3 and 4 indicated that the chance that screen and treat would be cost-effective at a cost-effectiveness threshold of \$50 000 was $39.5 \%, 63.2 \%, 58.4 \%$ and $58.1 \%$, respectively. At a cost-effectiveness threshold of $\$ 100000$, the chance of being cost-effective was $62.2 \%, 74.1 \%, 72.4 \%$ and $70.6 \%$, respectively.

\section{Exploratory analyses}

Sofosbuvir plus velpatasvir was not approved for reimbursement in most Canadian programs as of 2016. However, when we assumed treatment with 12 weeks of sofosbuvir plus velpatasvir for genotypes 4-6, the main results did not change significantly for any of the scenarios considered, and the main conclusions remained unaffected.

Earlier this year, the Canadian Agency for Drugs and Technologies in Health revised its guidelines for the economic evaluation of health technologies ${ }^{22}$ including reducing the discount rate from $5 \%$ to $1.5 \%$. In addition, the panCanadian Pharmaceutical Alliance has concluded successful negotiations with drug manufacturers to help jurisdictions expand access to publicly funded medications. ${ }^{23}$ When we repeated our analysis under these new assumptions (updated discount rate and no treatment reimbursement restrictions ${ }^{7}$ ), our main results changed significantly for all 4 scenarios. Under these conditions, the ICER for all scenarios ranged from \$15 821/QALY to \$24 736/QALY. Probabilistic sensitivity analyses indicated that the chance that screening would be cost-effective at the $\$ 50000$ cost-effectiveness threshold was $63.3 \%, 71.7 \%, 74.2 \%$ and $72.2 \%$ for scenarios $1,2,3$ and 4, respectively. Refer to Appendix 1, Supplementary Table 5 and Table 6 for the details on the exploratory analyses.

\section{Interpretation}

Our analyses suggest that, compared to the current situation in Canada, a one-time hepatitis $\mathrm{C}$ screening and treatment 


\section{Scenario 1}

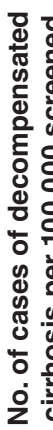

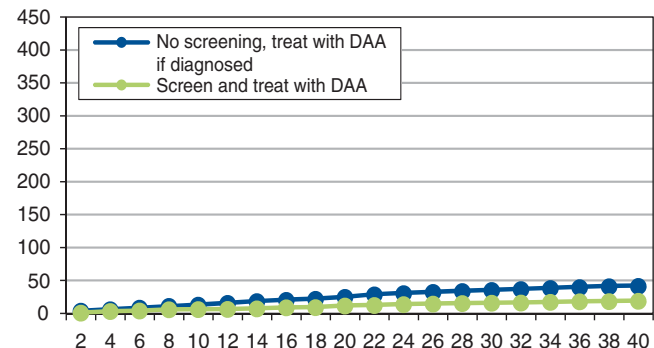

No. of years

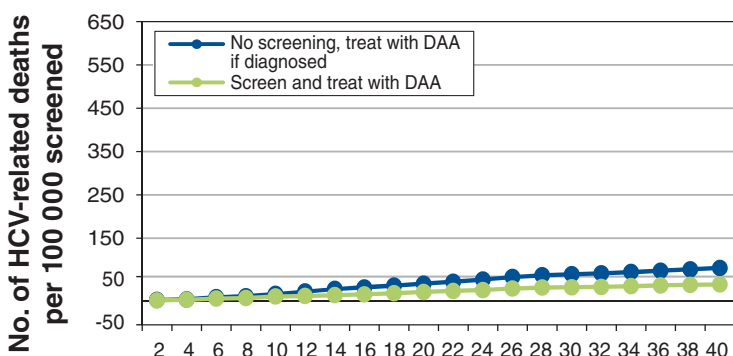

No. of years

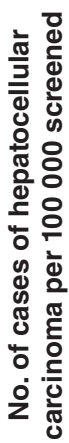

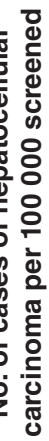

$\rightarrow$ No screening, treat with DA if diagnosed Screen and treat with DAA

Scenario 1: Asymptomatic people not at high risk for HCV infection

\begin{tabular}{|lccccc|}
\hline & Time, yr & $\begin{array}{c}\text { No. of cases of } \\
\text { DC }\end{array}$ & $\begin{array}{c}\text { No. of cases of } \\
\text { HCC }\end{array}$ & $\begin{array}{c}\text { No. of HCV- } \\
\text { related deaths }\end{array}$ & $\begin{array}{c}\text { No. of HCV- } \\
\text { related deaths } \\
\text { prevented }\end{array}$ \\
\hline $\begin{array}{l}\text { No screening, treat with } \\
\text { direct-acting antiviral if } \\
\text { diagnosed }\end{array}$ & 5 & 7.1 & 4.8 & 6.0 & - \\
\cline { 2 - 6 } & 10 & 13.1 & 9.5 & 13.9 & - \\
\cline { 2 - 6 } & 20 & 25.1 & 17.9 & 35.1 & - \\
\hline $\begin{array}{l}\text { Screen and treat with } \\
\text { direct-acting antiviral }\end{array}$ & \begin{tabular}{l} 
Lifetime \\
\cline { 2 - 6 }
\end{tabular} & 49.1 & 42.2 & 80.9 & - \\
\cline { 2 - 6 } & 10 & 6.8 & 2.0 & 2.6 & 3.4 \\
\hline & 20 & 11.9 & 5.1 & 8.4 & 5.5 \\
\hline Lifetime & 23.1 & 22.4 & 40.3 & 40.1 \\
\hline
\end{tabular}

Figure 2: Health events per 100000 people screened accumulated over time for scenario 1, asymptomatic people not at high risk for hepatitis $\mathrm{C}$ virus $(\mathrm{HCV})$ infection. Note: $\mathrm{DAA}=$ direct-acting antiviral, $\mathrm{DC}=$ decompensated cirrhosis, $\mathrm{HCC}=$ hepatocellular carcinoma.

\section{Scenario 2}

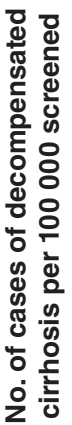

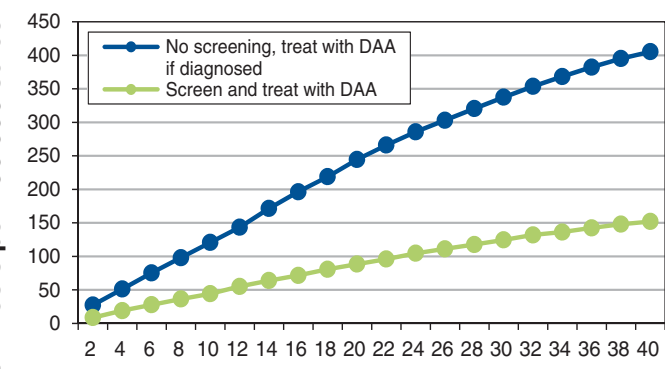

No. of years

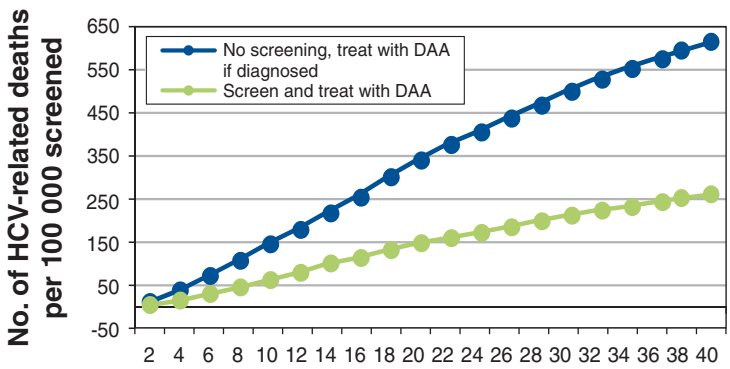

No. of years

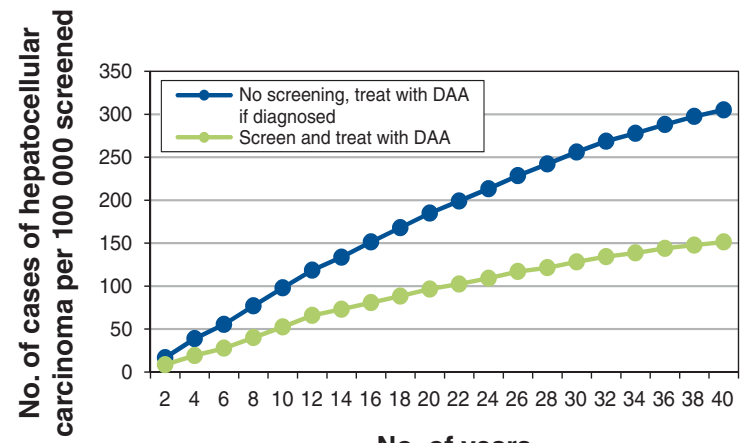

No. of years

\begin{tabular}{|lccccc|}
\hline Scenario 2: Immigrant populations with high prevalence & & & \\
\hline & Time, yr & $\begin{array}{c}\text { No. of cases of } \\
\text { DC }\end{array}$ & $\begin{array}{c}\text { No. of cases of } \\
\text { HCC }\end{array}$ & $\begin{array}{c}\text { No. of HCV- } \\
\text { related deaths }\end{array}$ & $\begin{array}{c}\text { No. of HCV- } \\
\text { related deaths } \\
\text { prevented }\end{array}$ \\
\hline $\begin{array}{l}\text { Strategy } \\
\text { direct-acting antiviral if } \\
\text { diagnosed }\end{array}$ & 5 & 64.5 & 47.4 & 55.1 & - \\
\cline { 2 - 6 } & 10 & 120.8 & 98.1 & 147.4 & - \\
\cline { 2 - 7 } & 20 & 245.6 & 186.0 & 339.8 & - \\
\hline $\begin{array}{l}\text { Screen and treat with } \\
\text { direct-acting antiviral }\end{array}$ & Lifetime & 465.9 & 343.9 & 731.7 & - \\
\cline { 2 - 6 } & 5 & 25.1 & 23.7 & 22.2 & 32.9 \\
\cline { 2 - 7 } & 10 & 44.2 & 52.5 & 63.3 & 84.1 \\
\hline
\end{tabular}

Figure 3: Health events per 100000 people screened accumulated over time for scenario 2, immigrant populations with high prevalence. Note: DAA = direct-acting antiviral, $\mathrm{DC}=$ decompensated cirrhosis, $\mathrm{HCC}=$ hepatocellular carcinoma, $\mathrm{HCV}=$ hepatitis $\mathrm{C}$ virus. 


\section{Scenario 3}
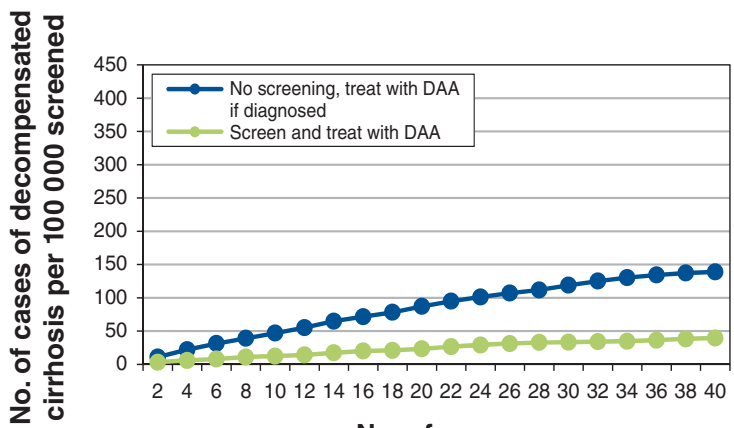

No. of years
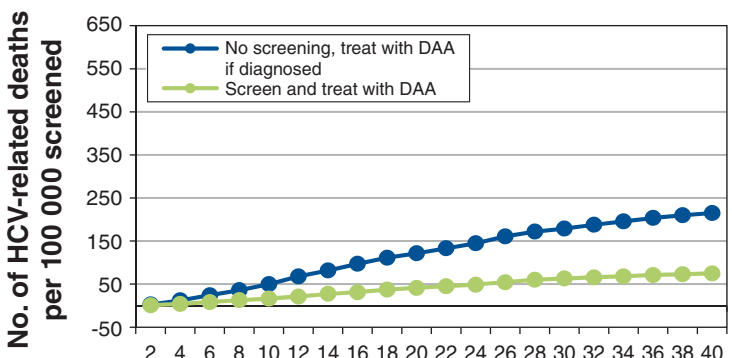

No. of years
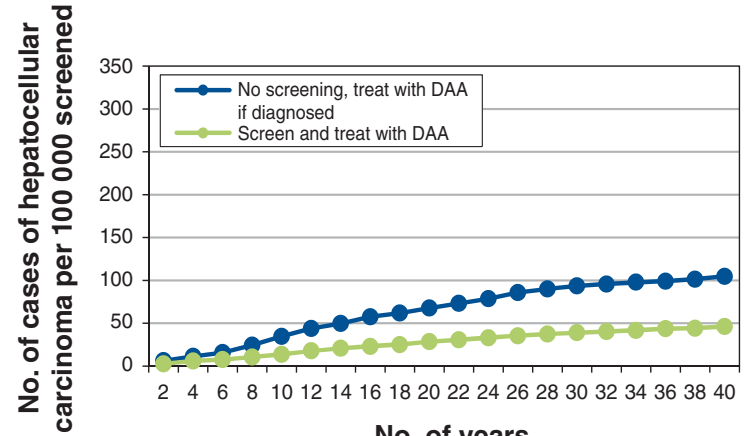

No. of years

\begin{tabular}{|c|c|c|c|c|c|}
\hline \multicolumn{6}{|c|}{ Scenario 3: Specific birth cohort (25-64 yr of age) } \\
\hline Strategy & Time, yr & $\begin{array}{c}\text { No. of cases of } \\
\text { DC }\end{array}$ & $\begin{array}{c}\text { No. of cases of } \\
\text { HCC }\end{array}$ & $\begin{array}{l}\text { No. of HCV- } \\
\text { related deaths }\end{array}$ & $\begin{array}{l}\text { No. of HCV- } \\
\text { related deaths } \\
\text { prevented }\end{array}$ \\
\hline \multirow{4}{*}{$\begin{array}{l}\text { No screening, treat with } \\
\text { direct-acting antiviral if } \\
\text { diagnosed }\end{array}$} & 5 & 25.9 & 12.3 & 17.6 & - \\
\hline & 10 & 46.9 & 34.7 & 49.9 & - \\
\hline & 20 & 87.6 & 67.7 & 121.5 & - \\
\hline & Lifetime & 150.9 & 112.2 & 237.7 & - \\
\hline \multirow{4}{*}{$\begin{array}{l}\text { Screen and treat with } \\
\text { direct-acting antiviral }\end{array}$} & 5 & 7.6 & 6.5 & 5.4 & 12.2 \\
\hline & 10 & 12.2 & 13.6 & 16.2 & 33.7 \\
\hline & 20 & 23.7 & 28.8 & 41.2 & 80.3 \\
\hline & Lifetime & 43.7 & 49.2 & 85.4 & 152.3 \\
\hline
\end{tabular}

Figure 4: Health events per 100000 people screened accumulated over time for scenario 3, specific birth cohort (25-64 yr of age). Note: $\mathrm{DAA}=$ direct-acting antiviral, $\mathrm{DC}=$ decompensated cirrhosis, $\mathrm{HCC}=$ hepatocellular carcinoma, $\mathrm{HCV}=$ hepatitis $\mathrm{C}$ virus.

\section{Scenario 4}
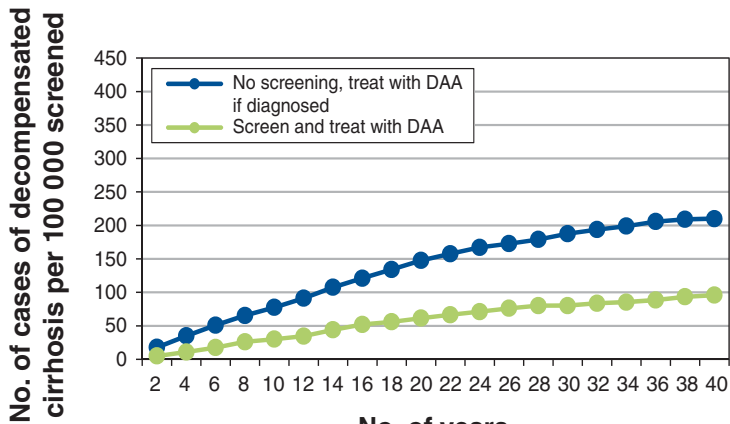

No. of years

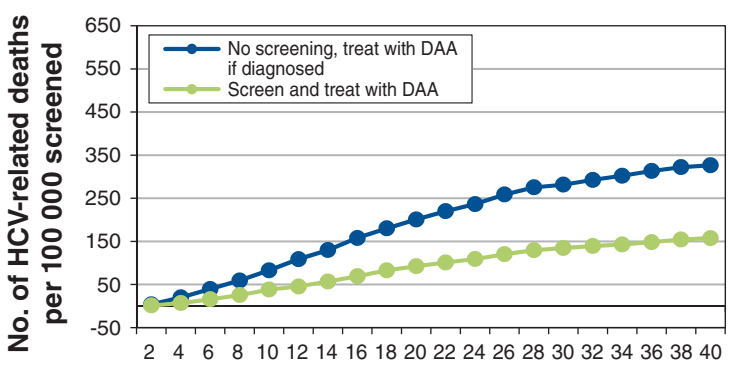

No. of years

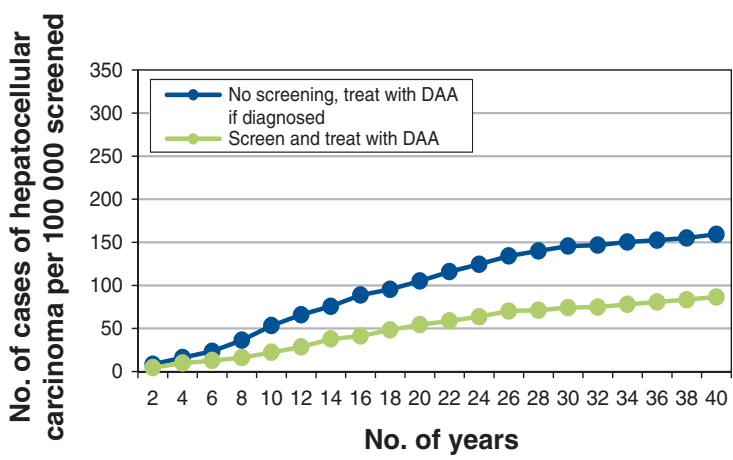

\begin{tabular}{|c|c|c|c|c|c|}
\hline Strategy & Time, yr & $\begin{array}{l}\text { No. of cases of } \\
\text { DC }\end{array}$ & $\begin{array}{c}\text { No. of cases of } \\
\text { HCC }\end{array}$ & $\begin{array}{l}\text { No. of HCV- } \\
\text { related deaths }\end{array}$ & $\begin{array}{l}\text { No. of HCV- } \\
\text { related deaths } \\
\text { prevented }\end{array}$ \\
\hline \multirow{4}{*}{$\begin{array}{l}\text { No screening, treat with } \\
\text { direct-acting antiviral if } \\
\text { diagnosed }\end{array}$} & 5 & 40.9 & 18.0 & 27.6 & - \\
\hline & 10 & 77.5 & 53.2 & 82.9 & - \\
\hline & 20 & 148.7 & 105.1 & 200.8 & - \\
\hline & Lifetime & 214.8 & 160.9 & 338.6 & - \\
\hline \multirow{4}{*}{$\begin{array}{l}\text { Screen and treat with } \\
\text { direct-acting antiviral }\end{array}$} & 5 & 14.7 & 10.7 & 9.8 & 17.7 \\
\hline & 10 & 30.1 & 22.3 & 38.2 & 44.7 \\
\hline & 20 & 63.0 & 54.8 & 92.4 & 108.5 \\
\hline & Lifetime & 97.9 & 88.6 & 170.5 & 168.1 \\
\hline
\end{tabular}

Figure 5: Health events per 100000 people screened accumulated over time for scenario 4, specific birth cohort (45-64 yr of age). Note: DAA = direct-acting antiviral, $\mathrm{DC}=$ decompensated cirrhosis, $\mathrm{HCC}=$ hepatocellular carcinoma, $\mathrm{HCV}=$ hepatitis $\mathrm{C}$ virus. 
program for scenarios 2-4 is likely to save lives and be costeffective, at \$31 468/QALY to \$34614/QALY gained over the lifetime of the cohort. The screening strategies that are most likely to be cost-effective are those focusing on immigrant populations with high prevalence (scenario 2), a birth cohort aged 25-64 years (scenario 3) and a birth cohort aged 45-64 years (scenario 4). On the other hand, screening and treatment programs targeting very low-risk populations (e.g., prevalence of $0.2 \%$ ) would be only marginally cost-effective, at $\$ 50490$ / QALY gained over the lifetime of the cohort. The conventional upper limit of cost-effectiveness thresholds varies among countries, from Can\$50 000/QALY to Can\$120 000/QALY.24-26 In terms of screening efficiency, scenario 2, in which 242 people would need to be screened to prevent $1 \mathrm{HCV}$-related death, would be the most attractive option.

A recent systematic review identified 7 cost-utility analyses on hepatitis $\mathrm{C}$ birth cohort screening and 5 for the general population from various countries. ${ }^{27}$ The results for screening birth cohorts ranged from Can\$5400 to Can\$65 749 per QALY gained, and the results for screening the general population ranged from Can $\$ 7900$ to Can $\$ 91000$ per QALY gained. However, most of the studies were conducted before interferon-free direct-acting antivirals became available, in 2014, and do not reflect the current treatment restriction situation.

In contrast to our model, which suggests that screening may offer clinical benefit and be economically attractive, the CTFPHC recently recommended against screening for HCV infection in adults who are not at elevated risk. ${ }^{8}$ The CTFPHC particularly pointed out 3 potential concerns: screening producing potential harm, weak evidence produced by the model and the budget impact of broader screening. We do not find the evidence regarding potential harm compelling. Our model integrates both the direct benefits and the harms of treatment, and clearly shows a net benefit for treatment. With respect to patient preferences for screening, the study commissioned by the CTFPHC, which used conservative estimates of screening benefit, suggested that screening was valued by participants and that perceptions of potential harm associated with screening, including potential stigma, were limited. Most of the participants in the report "would opt to be screened because they would rather know if they were HCV positive and take precautions not to infect others." ${ }^{8}$ Beyond preferences, guidelines must consider equity. About $8 \%$ of people with HCV infection will die from it, and many of these people are socially disadvantaged. ${ }^{28}$ Consideration of the consequences of allowing socially disadvantaged patients with a treatable illness to go unidentified and untreated must be thoughtfully integrated into policy recommendations.

The CTFPHC evaluated our model results using the Grading of Recommendations Assessment, Development and Evaluation (GRADE) approach ${ }^{8}$ and considered them as "weak evidence." However, the GRADE approach was not developed to evaluate decision and economic models, and has limited utility for that purpose. ${ }^{29}$ In our view, models are the strongest scientific method for simultaneously considering the aggregate benefit and cost of health interventions and are of particular value when only indirect evidence is available, as is the case here. Our model has been validated extensively and is populated by good-quality data on prognosis, effectiveness, utility and cost, in addition to review for sensibility by clinical experts. Given the absence of direct evidence available for screening benefit now and into the foreseeable future, we believe that modelling is the most reliable way, at present, to weigh the risks and benefits of screening.

Where we do agree with the CTFPHC is on the question of budget impact. Without doubt, screening will impose a substantial burden on public and private drug plans and individuals. Aggregate cost is the most compelling argument against screening in 2017.

Other countries have "grasped the nettle" of HCV control. Australia has plans to "eradicate the deadly and debilitating disease within a generation." ${ }^{30}$ In the United States, the Centers for Disease Control and Prevention recommend birth cohort screening (1945-1965, aged 50-69 years in 2014) for hepatitis $\mathrm{C}$ in addition to risk-based screening. ${ }^{31}$ The World Health Organization's Strategy on Viral Hepatitis, to which Canada is a signatory, calls for a $90 \%$ reduction in new cases of chronic $\mathrm{HCV}$ infection, a $65 \%$ reduction in $\mathrm{HCV}$-related deaths and treatment of $80 \%$ of eligible people. ${ }^{32}$

\section{Limitations}

Our analysis is based on a case-finding screening program rather than universal screening of the population. In addition, the utilities of chronic $\mathrm{HCV}$ infection in patients with decompensated cirrhosis and hepatocellular carcinoma were based on small samples and may not cover the full spectrum of disease severity. Furthermore, the prevalence provided by the CTFPHC ( $0.2 \%)$ that was used in the analysis for scenario 1 is low. ${ }^{4} \mathrm{We}$ believe that screening the general population would likely identify many people who meet high-risk criteria but have never been screened. A recent prevalence study conducted in Ontario showed a prevalence of greater than $1 \%$ for people born between 1945 and 1974. ${ }^{33}$ Thus, our analysis likely underestimates both the clinical benefits and the economic attractiveness of universal screening. Last, our analyses did not consider coinfected patients and subsequent treatment of reinfected people.

\section{Conclusion}

Our model suggests that some form of a one-time hepatitis C screening and treatment program may be cost-effective for Canada. Besides cost-effectiveness, screening policy will also need to consider the aggregate health gains and budget impact of screening strategies as well as the effects of screening on patients' values and experiences and health equity. In the future, although sustained virologic response rates are not likely to improve substantially, drug prices will likely fall owing to price competition and negotiated agreements. In addition, better estimates of prevalence as well as evidence of long-term treatment benefit may become available. Therefore, an update of the analysis and of the screening recommendation will likely become necessary.

\section{References}

1. Kwong JC, Crowcroft NS, Campitelli MS, et al.; Ontario Burden of Infectious Disease Study Advisory Group. Ontario Burden of Infectious Disease Study (ONBOIDS): an OAHPP/ICES report. Toronto: Ontario Agency for Health Protection and Promotion, Institute for Clinical Evaluative Sciences; 2010. 
2. Rotermann M, Langlois K, Andonov A, et al. Seroprevalence of hepatitis B and C virus infections: results from the 2007 to 2009 and 2009 to 2011 Canadian Health Measures Survey. Health Rep 2013;24:3-13.

3. Trubnikov M, Yan P, Archibald C. Estimated prevalence of hepatitis C virus infection in Canada, 2011. Can Commun Dis Rep 2014;40:429-37.

4. Shah HA, Heathcote J, Feld JJ. A Canadian screening program for hepatitis C: Is now the time? CMA7 2013;185:1325-8.

5. Wong WW, Tu HA, Feld JJ, et al. Cost-effectiveness of screening for hepatitis C in Canada. CMA7 2015;187:E110-81.

6. Wong WW, Lee KM, Singh S, et al. Drug therapies for chronic hepatitis C infection: a cost-effectiveness analysis. CMA7 Open 2017;5:E97-108.

7. Marshall AD, Saeed S, Barrett L, et al. Restrictions for reimbursement of direct-acting antiviral treatment for hepatitis $\mathrm{C}$ virus infection in Canada: a descriptive study. CMA7 Open 2016;4:E605-14

8. Canadian Task Force on Preventive Health Care. Recommendations on hepatitis C screening for adults. CMA7 2017;189:E594-604.

9. Wong WWL, Krahn M, Lee K, et al. CADTH Therapeutic Review. Drugs for chronic hepatitis $C$ infection: cost-effectiveness analysis. Ottawa: Canadian Agency for Drugs and Technologies in Health; 2016.

10. Census profile. 2011 census. Ottawa: Statistics Canada; 2012. Cat no 98-316-XWE.

11. CADTH Therapeutic Review. Drugs for chronic bepatitis $C$ infection: clinical report. Ottawa: Canadian Agency for Drugs and Technologies in Health; 2015.

12. Hasan F, Asker H, Al-Khaldi J, et al. Peginterferon alfa-2b plus ribavirin for the treatment of chronic hepatitis C genotype 4. Am 7 Gastroenterol 2004;99:1733-7.

13. Alfaleh FZ, Hadad Q, Khuroo MS, et al. Peginterferon alpha-2b plus ribavirin compared with interferon alpha-2b plus ribavirin for initial treatment of chronic hepatitis C in Saudi patients commonly infected with genotype 4 . Liver Int 2004;24:568-74.

14. Kamal SM, El Tawil AA, Nakano T, et al. Peginterferon \{alpha\}-2b and ribavirin therapy in chronic hepatitis $\mathrm{C}$ genotype 4 : impact of treatment duration and viral kinetics on sustained virological response. Gut 2005;54:858-66.

15. Ontario's use of funding provided by the federal hepatitis $\mathrm{C}$ undertaking agreement. Toronto: Government of Ontario; 2007.

16. Myers RP, Shah H, Burak KW, et al. An update on the management of chronic hepatitis C: 2015 consensus guidelines from the Canadian Association for the Study of the Liver. Can 7 Gastroenterol Hepatol 2015;29:19-34.

17. TreeAge 2013 Professional. Williamstown (MA): TreeAge Software; 2013.

18. Krahn M, Wong JB, Heathcote J, et al. Estimating the prognosis of hepatitis C patients infected by transfusion in Canada between 1986 and 1990. Med Decis Making 2004;24:20-9.

19. Salomon JA, Weinstein MC, Hammitt JK, et al. Cost-effectiveness of treatment for chronic hepatitis $\mathrm{C}$ infection in an evolving patient population. 7AMA 2003;290:228-37.

20. Wong JB, Bennett WG, Koff RS, et al. Pretreatment evaluation of chronic hepatitis C: risks, benefits, and costs. $7 A M A$ 1998;280:2088-93.

21. Chahal HS, Marseille EA, Tice JA, et al. Cost-effectiveness of early treatment of hepatitis $\mathrm{C}$ virus genotype 1 by stage of liver fibrosis in a US treatmentnaive population. 7AMA Intern Med 2016;176:65-73.

22. Guidelines for the economic evaluation of bealth technologies: Canada. 4th ed. Ottawa: Canadian Agency for Drugs and Technologies in Health; 2017.

23. A statement from the pan-Canadian Pharmaceutical Alliance [press release]. Ottawa: Pan Canadian Pharmaceutical Alliance. 2017 Feb. 21.

24. Laupacis A, Feeny D, Detsky AS, et al. How attractive does a new technology have to be to warrant adoption and utilization? Tentative guidelines for using clinical and economic evaluations. CMAJ 1992;146:473-81.
25. McCabe C, Claxton K, Culyer AJ. The NICE cost-effectiveness threshold: what it is and what that means. Pharmacoeconomics 2008;26:733-44.

26. Choosing interventions that are cost effective (WHO-CHOICE). Geneva: World Health Organization; 2005.

27. Coward S, Leggett L, Kaplan GG, et al. Cost-effectiveness of screening for hepatitis C virus: a systematic review of economic evaluations. BM7 Open 2016;6:e011821.

28. Jones AA, Vila-Rodriguez F, Leonova O, et al. Mortality from treatable illnesses in marginally housed adults: a prospective cohort study. BMF Open 2015;5:e008876.

29. Rehfuess EA, Akl EA. Current experience with applying the GRADE approach to public health interventions: an empirical study. BMC Public Health 2013;13:9.

30. Turnbull Government invests over $\$ 1$ billion to cure HEP C [press release]. Australia: Minister of Health, Commonwealth of Australia; 2015.

31. Smith BD, Morgan RL, Beckett GA, et al. Recommendations for the identification of chronic hepatitis $\mathrm{C}$ virus infection among persons born during 1945-1965. MMWR Recomm Rep 2012;61:1-32.

32. World Hepatitis Summit harnesses global momentum to eliminate viral hepatitis [press release]. Glasgow (UK): World Health Organization; 2015 Sept. 2.

33. Bolotin S, Garber G. Public Health Ontario grand rounds: population-based estimate of hepatitis $\mathrm{C}$ virus prevalence in Ontario [presentation]. Toronto: Ontario Public Health Conference; 2016 Nov. 29.

Affiliations: School of Pharmacy (Wong), University of Waterloo, Kitchener, Ont.; Toronto Health Economics and Technology Assessment Collaborative (Wong, Erman, Krahn), Leslie Dan Faculty of Pharmacy and Toronto Centre for Liver Disease (Feld), University Health Network, University of Toronto, Toronto, Ont.

Contributors: William Wong implemented the model, collected and analyzed the data, and drafted the manuscript. Aysegul Erman contributed to the collection and analysis of the data. Jordan Feld and Murray Krahn contributed to the design of the study and the analysis and interpretation of the data. All of the authors contributed to the revision of the manuscript for important intellectual content, gave final approval of the version to be published and agreed to be accountable for all aspects of the work.

Funding: Funding for this study was provided by the Public Health Agency of Canada (PHAC). The Canadian Task Force on Preventive Health Care (CTFPHC) Working Group suggested some assumptions and scenarios to be evaluated in this manuscript. However, the views expressed in this article are those of the authors alone and do not represent the positions of the CTFPHC or the PHAC.

Acknowledgment: The authors express their appreciation to the Canadian Task Force on Preventive Health Care Working Group for their valuable suggestions and insights.

Supplemental information: For reviewer comments and the original submission of this manuscript, please see www.cmajopen.ca/content $/ 5 / 3$ / E662/suppl/DC1 